\title{
THE EFFECTS OF MUTUALISTIC ANTS ON APHID LIFE HISTORY TRAITS
}

\author{
Thomas Flatt and WolfGang W. Weisser ${ }^{1}$ \\ Zoology Institute, University of Basel, Rheinsprung 9, 4051 Basel, Switzerland
}

\begin{abstract}
The relationship between homopterans and ants is generally thought to be mutualistic, as both partners seem to benefit from an association. In aphids, previous studies have shown that ant tending improves the survival and reproduction of aphid colonies, mainly by protection of aphids from enemy attack. However, the effects of ant tending on the fitness of individual aphids have rarely been addressed. We investigated the effects of ant tending on life history traits of aphids feeding singly on a host plant, in the absence of natural enemies. A factorial design allowed us to control for variation in the level of tending effort among individual ant colonies. The presence of workers of the ant Lasius niger had a strong positive effect on the fitness of individuals of the aphid Metopeurum fuscoviride. Ant-tended individuals lived longer, matured earlier, had a higher rate of reproduction, and a higher expected number of offspring than aphids not tended by ants. An aphid's longevity was significantly correlated with the daily mean number of workers tending it. The strong dependence of aphid fitness on the level of ant tending shows that ants can influence aphid life history traits even when aphids occur singly on plants.
\end{abstract}

Key words ant; ant tending; aphid; Homoptera; honeydew; Lasius niger; Metopeurum fuscoviride; mutualistic relationship; myrmecophily.

\section{INTRODUCTION}

Many species of phytophagous insects such as homopterans (i.e., aphids, coccids, and membracids) and lepidopteran larvae (lycaenids and riodinids) are mutualistically associated with ant species (e.g., Herzig 1937, Nixon 1951, Way 1963, Carrol and Janzen 1973, Pierce and Easteal 1986, Buckley 1987a, b, Hölldobler and Wilson 1990). Tended herbivores are generally assumed to be important food resources for many ant species, because their secretions contain energy-rich nutrients (Carrol and Janzen 1973, Hölldobler and Wilson 1990). For instance, tending ants regularly feed upon the carbohydrate-rich "honeydew" of homopterans or upon sugars and amino acids produced in the exocrine dorsal nectary glands of some myrmecophilous butterfly larvae (e.g., Buckley, 1987a, b, Fiedler and Maschwitz 1988). Several studies have provided evidence that ants benefit from associations with herbivores in terms of energy gain, which is thought to result in higher colony growth rates (Degen et al. 1986, Pierce et al. 1987, Fiedler and Maschwitz 1988, Cushman and Beattie 1991). In turn, ants often act as guards and decrease the impact of predators and parasitoids on the fitness of their hosts (El-Ziady and Kennedy 1956, Banks 1962, Way 1963, Banks and Macaulay 1967, Addicott 1979, Pierce and Mead 1981, Buckley $1987 a, b$, Völkl 1992). Ant tending may therefore considerably reduce mortality risks and thus provides a selective advantage. In the lycaenid butterfly Jalmenus

Manuscript received 1 March 1999; revised 22 November 1999; accepted 2 December 1999.

${ }^{1}$ Corresponding author. Present address: Institute of Ecology, Friedrich-Schiller-University, Dornburger Strasse 159, 07743 Jena, Germany. evagoras, caterpillars are protected against parasitoid wasps and arthropod predators by Iridomyrmex ants (Pierce et al. 1987). Similarly, protection from predators and parasitoids is likely to be the most important benefit for the survival of tended aphid colonies since predators are capable of rapidly decreasing or even eliminating whole colonies when not checked by ants (Banks 1962, Way 1963, Buckley 1987a, b, Dixon 1998).

In experiments in which aphid colonies were reared in the presence and absence of ants, the ant mutualists beneficially affected life history characteristics of their aphid hosts. Tending promotes reproductive performance (e.g., El-Ziady and Kennedy 1956, Banks 1958, El-Ziady 1960; Buckley 1987a, b), faster developmental rates (e.g., El-Ziady 1960), or colony growth (e.g. El-Ziady and Kennedy 1956, Buckley $1987 a, b)$. Mechanistically, ant-tended aphids may benefit from increased feeding and excretion rates (e.g., Herzig 1937, Banks and Nixon 1958, Mittler 1958, Takeda et al. 1982) and from the removal of their honeydew, which reduces the mortality risk caused by fungal attack (Nixon 1951, Buckley 1987a, b).

For ant tending to be favored by selection, net costs to tended aphids need to be smaller than benefits. Although most studies have found an overall positive effect of tending ants on aphids at the level of the population, a recent study suggests that ant tending may also be costly for aphids (Stadler and Dixon 1998). In the absence of natural enemies, tended Aphis fabae feeding on plants in small groups of 10-15 individuals suffered from longer developmental times and smaller growth rates, delayed offspring production, smaller gonads, and fewer embryos. Recent studies also suggest 
that benefits of mutualistic associations are densitydependent (Bronstein 1994). For example, the positive effect of ant tending on the growth rate of aphid populations has been shown to decline at higher aphid densities (e.g., Breton and Addicott 1992a). These results have two implications. First, the results suggest that benefits at the population level may not reflect benefits at the individual level. On the one hand, benefits measured in terms of population growth rate are a secondary result of the underlying variation in individual-level fitness, and it is generally difficult to recover this underlying variation from population level measures. On the other hand, even if life history traits are analyzed at the population level, density-dependence may confound measurements of individual-level fitness. Second, the results suggest that ant tending can be costly at the individual level in the absence of natural enemies.

In this paper, we investigate the effect of the presence of honeydew-collecting workers of the ant Lasius niger on life history traits and fitness of individuals of the aphid Metopeurum fuscoviride in the absence of natural enemies. Because of density-dependence in the interaction between aphid and ants, it is important to examine the effects of ant tending on aphid fitness not only for aphid populations of various sizes, but also for individuals feeding singly on a host plant. We address the question of whether ant tending is beneficial at the individual level for aphids feeding singly on a host plant, in an aphid species that is usually found tended by ants in the field.

\section{Methods}

\section{Study system}

For our experiments we chose Metopeurum fuscoviride Stroyan, a monophagous, holocyclical aphid species of the common tansy, Tanacetum vulgare L. (Asteraceae), a perennial herbaceous composite from $\mathrm{Eu}-$ rope and Asia (Börner 1952, Klausnitzer 1968, Mitich 1992). M. fuscoviride is regularly tended by ants, of which Lasius niger (L.) is the most common (Mackauer and Völkl 1993, Fischer 1997; W. W. Weisser, personal observation). Untended colonies of $M$. fuscoviride can regularly be found in the field, particularly in places with moist soils that do not support colonies of the xerothermic L. niger or other ant species (e.g., Mackauer and Völkl 1993). We used four ant colonies collected at a field site near Basel, Switzerland, in early May 1998. Each colony had several hundred workers. All colonies were kept in plastic nest boxes $(45 \times 34$ $\times 10.5 \mathrm{~cm})$ or buckets $(10 \mathrm{~L}$ in volume) coated with fluon (Northern Products, Incorporated, Woonsocket, Rhode Island, USA) and talcum powder, and filled with natural substrate. All colonies had access to plants hosting $M$. fuscoviride aphids to provide ants with sufficient carbohydrate. Ants were regularly fed with mealworms (larvae of Tenebrio mollitor), freshly killed fruit flies
(Drosophila melanogaster), and artificial ant diet ("food cubes"; Keller et al. 1989). Ant colonies were regularly sprayed with tap water to avoid dessiccation. Ramets of the host plant (T. vulgare) were individually planted in a commercial growing medium (TKS 2, Floragard VertriebsGmbH, D-26129 Oldenburg, Germany) in $360-\mathrm{mL}$ pots several weeks prior to the start of the experiment.

\section{General experimental design}

Thirty-two experimental plants (height $20-40 \mathrm{~cm}$ ) were placed on four tables ( $=$ blocks; eight replicates per block, table size $=150 \times 100 \mathrm{~cm})$. The plants were each placed on a piece of foam rubber $(30 \times 30 \mathrm{~cm})$ and enclosed in a transparent plastic tube $(25 \mathrm{~cm}$ in diameter, $63 \mathrm{~cm}$ in height). The tops of these tubes were tightly covered with fine gauze mesh to prevent the escape of animals. On each table, we randomly assigned four plants to the ant-tending treatment and four to the control (=ant-exclusion $=$ untended $)$. The position of the plants on the tables was chosen prior to allocating the plants to treatment or control. Each of the four ant colonies was assigned to one of the four tables. Workers of L. niger had access to the plants of the ant-tended treatment via transparent plastic tubes ( $1 \mathrm{~cm}$ in diameter, $2 \mathrm{~m}$ of tube per table) that connected the container housing the ant colony to the four cages. The four cages containing the replicates from the control were not connected to the ant colony.

The experiment was started on 24 May 1998 by assigning one winged adult female aphid collected from plants growing outside in the garden of the Zoology Institute, Basel, to each of the 32 experimental plants. After they were allowed to reproduce for $24 \mathrm{~h}$, the mothers and all but one sibling were removed, leaving only a single offspring on each of the 32 plants. Thus, we investigated the effects of ant tending on life history traits of single unwinged individuals that were born on a plant, by a winged mother. The experiment was carried out in a climate chamber with a light:dark cycle of $18: 6 \mathrm{~h}$, a temperature of $21^{\circ} \pm 2^{\circ} \mathrm{C}$ (mean $\left.\pm 1 \mathrm{SD}\right)$ and an approximate relative air humidity of $65 \%$. Light intensity at plant height was $~ 5000$ lux.

\section{Removal of aphids by ants}

For our analysis of aphid life-span we assumed that aphids not found in the enclosure had died. No escape of aphids was possible from enclosures not connected to the ant colonies. In the ant-tended replicates it was possible for foraging ants to remove dead aphids. To test whether ants would remove dead aphids and carry them to their nests we performed the following experiment. We offered each ant colony five bodies of $M$. fuscoviride and, as a control, five bodies of the pea aphid Acyrtosiphon pisum (Harris) in a petri dish. Over a period of two hours we counted all remaining aphids, in 30-min intervals. In our experiment, we could not exclude the possibility that ants would incidentally kill 
aphids and carry them to their nest. However, this was never observed and we consider this possibility highly unlikely, because ant colonies were regularly provided with sources of protein in our experiment (e.g., Way 1963).

\section{Effect of origin on experimental animals}

We assumed that there were no significant a priori differences among the winged mothers we used to obtain experimental animals. We tested this assumption by measuring the fresh body mass and hind tibia length of all mothers.

\section{Aphid life history traits}

Each individual aphid was checked daily at the same time, over its whole life-span. For each individual we recorded survival and the number of offspring produced during the last $24 \mathrm{~h}$. Any offspring produced was carefully removed from the plant using a fine brush. From the data we calculated age at maturity (=age at first reproduction, Stearns 1992), life-span (=age at death), lifetime fecundity and rate of reproduction (=lifetime fecundity/(age at death - age at maturity)). Data were collected over 48 consecutive days, that is until the last aphid in the experiment had died.

\section{Level of ant tending}

To quantify the level of ant tending we counted the number of ant workers tending the experimental aphid daily when we controlled aphid survival and fecundity. For each replicate we calculated the ant tending rate as the number of ant workers tending an aphid averaged over the lifetime of the aphid.

\section{Honeydew removal}

To quantify the effect of ants on the removal of honeydew we daily checked whether a honeydew droplet was visible at the cauda of an aphid or somewhere on the plant close to the aphid. We calculated the rate at which honeydew droplets were found by dividing the total number of honeydew droplets observed during the lifetime of an individual by aphid life span.

\section{Movements and disturbances of aphids}

To investigate whether ant tending would affect the movements of the aphids on the plants we made daily records of the exact position of an aphid on a sketch of the host plant. For each replicate we calculated the rate of movement as the total number of movements observed divided by life span. We predicted that untended aphids would change their feeding position on the plant more often than tended ones because untended M. fuscoviride cannot dispose of honeydew by kicking the droplets away using a hind leg. Additionally, we recorded if an aphid moved to a different feeding site or dropped off the host plant as a reaction to the disturbances caused by the daily checks. M. fuscoviride is known to have a well-developed dropping reflex (e.g., Fischer 1997). We calculated the rate of reaction to disturbances of a replicate as the total number of such reactions observed divided by aphid life span. If an aphid dropped off the plant it was replaced to its previous location.

\section{Statistical analysis}

Statistical analyses and significance tests $(P<0.05)$ were performed by following procedures described in Sokal and Rohlf (1995) and using SAS v.6.12 (SAS Institute 1989). Prior to analysis, all data were tested for homogeneity of variances using the $F_{\max }$ test. We checked for normality of residuals by using the procedure UNIVAR implemented in SAS. If the assumptions were violated, we transformed the data as necessary. We analyzed the effect of ant tending on aphid life history traits and fitness by performing two-way ANOVAs using Type III sums of squares for data from our randomized-block design. Ant tending (presence/ absence) entered the analysis as a fixed effect, whereas blocks (=tables) were treated as a random effect. In our experimental design we could distinguish between ant colony effects and other blocking (table) effects only by comparing the performance of ant-tended and untended aphids separately. In the two-way ANOVAs we therefore computed main effects only. We used oneway ANOVAs when separately analyzing the effects of ant colony or table identity.

\section{REsults \\ Removal of aphids by ants}

Workers in each of the four ant colonies removed all offered aphid bodies (5 M. fuscoviride, 5 A. pisum) within two hours of observation. Thus, foraging ants are likely to remove dead aphids from an enclosure, suggesting that ant-tended aphids not found in the enclosure had died and were carried to the ant colony.

\section{Effect of origin of experimental animals}

There were no significant differences among the winged mothers of experimental aphids with respect to their body mass (ants: $F_{1,22}=0.18, P=0.68$; blocks: $F_{3,22}=0.76, P=0.53$ ) or hind tibia length (ants: $F_{1,21}$ $=0.32, P=0.58$; blocks: $\left.F_{3,21}=0.19, P=0.90\right)$. Thus, there were no systematic differences among the animals used in the experiment that were due to differences among mothers.

\section{Effects of ant tending on aphid life history traits}

Life-span.-Ant-tended aphids lived on average nine days longer than untended aphids (Fig. 1A, ants: $F_{1,27}$ $=6.45, P=0.017$; blocks: $\left.F_{3,27}=1.64, P=0.20\right)$. There were no significant differences among ant colonies in the tending rates of aphids $\left(F_{3,12}=1.68, P=\right.$ 0.23 , ant-tending rate log-transformed). Aphid life span was significantly correlated with ant-tending rate in tended aphids (Fig. 2, $r=0.80, n=16, P<0.001$, rate log-transformed). 

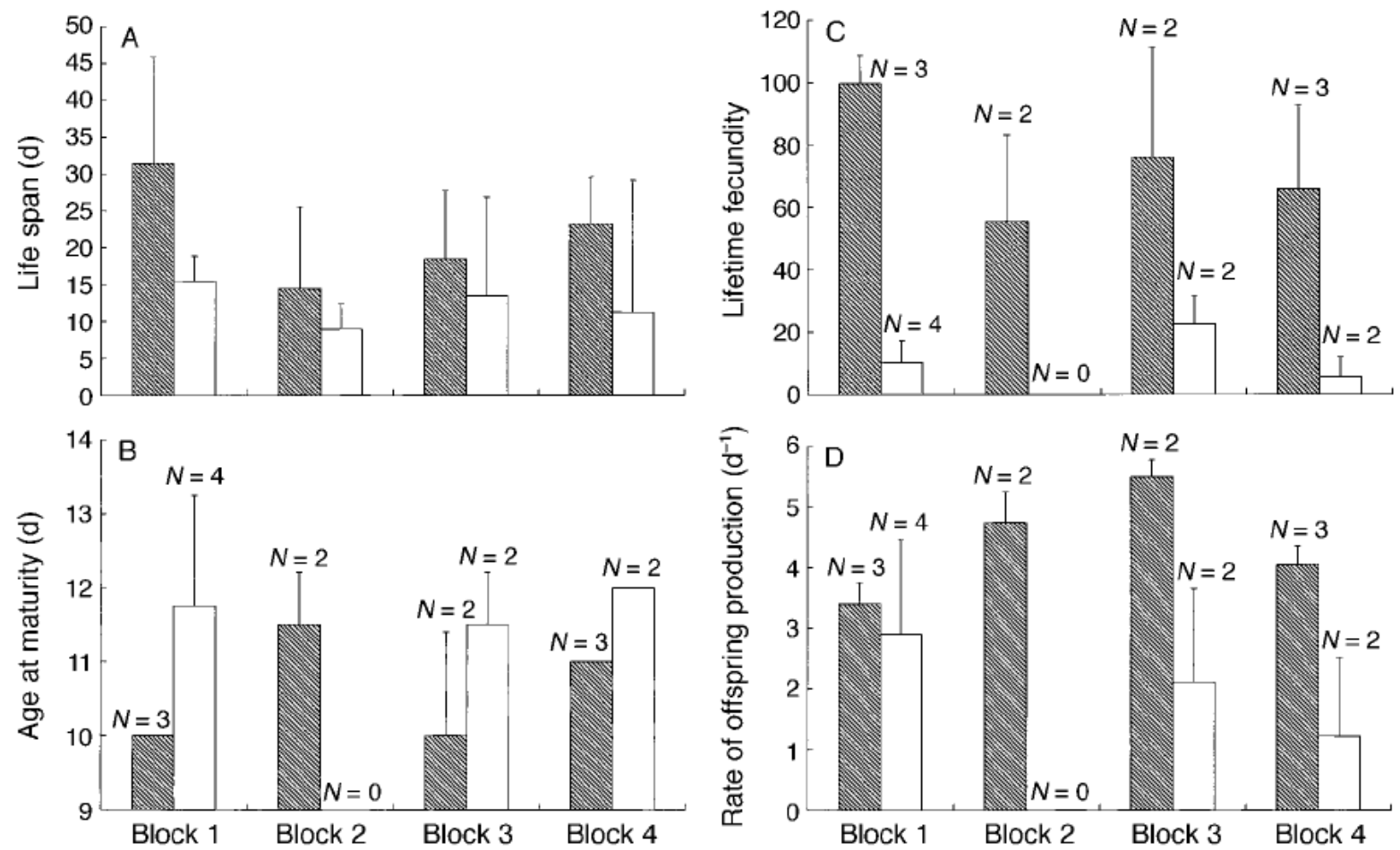

FIG. 1. The effect of ant tending on life history traits of $M$. fuscoviride. Histograms show means and standard deviations Hatched bars represent ant-tended aphids; open bars represent untended aphids. (A) Aphid life span, $N=4$ for each block/ treatment combination; (B) age at maturity (individual aphids that survived until maturity); (C) lifetime fecundity; (D) rate of reproduction. In (B), (C), and (D), only reproducing individuals were considered. Originally, $N=4$ for each block/ treatment combination. Smaller sample sizes $(N<4)$ indicate block/treatment combinations where some individuals did not survive to reproduce.

We did not find significant differences in longevity of aphids among the experimental blocks, when only the ant-tended aphids were included in the analysis $\left(F_{3,12}=1.16, P=0.36\right)$. Similarly, there were no significant differences in longevity of aphids among blocks for the untended aphids $\left(F_{3,12}=0.52, P=0.68\right)$.

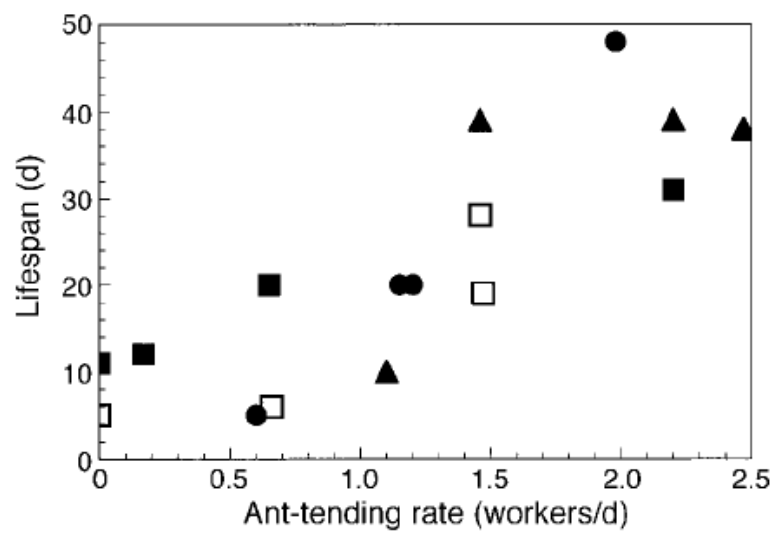

FIG. 2. The relationship between aphid life span and anttending rate (mean number of ant workers tending an aphid) for ant-tended individuals only. $N=4$ for each block. Solid triangles $=$ block 1 ; open squares $=$ block 2 ; solid squares = block 3 ; solid circles $=$ block 4 .
Age at maturity.-Ant-tended aphids matured on average one day earlier than aphids not tended by ants (Fig. 1B, ants: $F_{1,13}=10.63, P=0.006$; blocks: $F_{3,13}$ $=1.6, P=0.24)$. Because in several blocks all replicates had the same age at maturity (Fig. 1 B), variances were zero in these cases, causing heterogeneity of variances. We therefore performed a one-way ANOVA, ignoring block effects (ants: $F_{1,16}=6.77, P=$ 0.019).

Reproductive success.-Ant-tended aphids produced on average 63 more offspring than untended aphids (Fig. 1C, ants: $F_{1,13}=52.29, P<0.001$; blocks: $F_{3,13}$ $=1.87, P=0.19$ ). The rate of reproduction of anttended aphids was $\sim$ twice the rate of reproduction of untended aphids (Fig. 1D, ants: $F_{1,13}=9.54, P=0.009$; blocks: $F_{3,13}=0.66, P=0.59$; only individuals surviving until maturity were considered in these two analyses).

There were no significant differences among experimental blocks in lifetime fecundity or rate of reproduction, when tended and untended aphids were analyzed separately (ant-tended replicates: lifetime fecundity $F_{3,6}=1.56, P=0.29$, rate of reproduction $F_{3,6}=$ $3.0, P=0.12$; untended replicates: lifetime fecundity $F_{2,5}=2.98, P=0.14$, rate of reproduction $F_{2,5}=0.98$, $P=0.44$; reproducing aphids only). 
Life-span was significantly correlated with lifetime fecundity $\left(r_{\mathrm{S}}=0.86, n=18, P<0.001\right.$; reproducing aphids only). The correlation remained significant when tended and untended aphids were analyzed separately (ant-tended replicates: $r_{\mathrm{S}}=0.88, n=10, P=$ 0.005; untended replicates: $r_{\mathrm{S}}=0.79, n=8, P=0.02$; reproducing individuals only). Life-span was not significantly correlated with rate of reproduction when both tended and untended aphids were considered $\left(r_{\mathrm{S}}\right.$ $=0.16, n=18, P=0.52)$ and when untended aphids were analyzed separately $\left(r_{\mathrm{S}}=0.07, n=8, P=0.87\right)$. However, the correlation was significant and negative for ant-tended replicates, suggesting that reproductive output decreased over the life span in longer-lived aphids $\left(r_{\mathrm{S}}=-0.8, n=10, P=0.005\right)$. Thus, longlived aphids had a higher fecundity than short-lived aphids, because they lived longer.

There was a significant positive correlation between lifetime fecundity and ant-tending rate in tended aphids $(r=0.86, n=16, P<0.001)$. This result remained significant when only reproducing individuals were included in the analysis $(r=0.80, n=10, P=0.006$; rates $\log$-transformed in both analyses). The rate of reproduction was not significantly correlated with anttending rate $\left(r_{\mathrm{S}}=-0.42, n=10, P=0.22\right.$; only reproducing individuals). Thus, in ant-tended aphids the higher lifetime fecundity of individuals that were tended more intensively was a consequence of those aphids living longer, i.e., reproducing for a longer period of time.

Honeydew removal. - On average $5.7 \pm 5.4$ honeydew droplets (mean $\pm 1 \mathrm{SD}$ ) were observed during the lifetime of an untended aphid, whereas only $0.75 \pm 1.2$ droplets were counted for ant-tended individuals. This corresponded to mean rates of $0.36 \pm 0.26$ and $0.05 \pm$ 0.10 droplets/day for untended and ant-tended individuals, respectively (ants: $F_{1,27}=17.74, P<0.001$; blocks: $F_{3,27}=0.16, P=0.92$ ). Honeydew droplets were observed only in six tended individuals and the correlation between aphid life span and the rate of honeydew appearance was not significant in tended aphids $\left(r_{\mathrm{S}}=\right.$ $-0.12, n=16, P=0.65)$. However, there was a significant positive relationship between aphid life span and the rate at which honeydew droplets were found in untended aphids $\left(r_{\mathrm{S}}=0.64, n=16, P=0.007\right)$.

\section{Movements and disturbances of aphids}

There were no significant differences in the rates of movement between ant-tended $(0.33 \pm 0.16)$ and untended aphids $\left(0.29 \pm 0.20\right.$ movements/d) (ants: $F_{1,27}$ $=0.57, P=0.46$; blocks: $\left.F_{3,27}=1.0, P=0.41\right)$. This is in contrast to our expectation that ant tending reduces the number of movements of aphids on the plant.

The daily check of the replicates rarely caused a measurable disturbance to the aphids. Aphids in the ant-tended treatment moved or dropped off the host plant during checks on average only every seventh day, and in untended replicates on average every 11 th day (rate of reaction to disturbance in ant-tended treatment: $0.14 \pm 0.12$, untended treatment: $0.086 \pm 0.10$ movements/d, ants: $F_{1,27}=1.97, P=0.17$; blocks: $F_{3,27}=$ 3.97, $P=0.38)$.

\section{DISCUSSION}

Benefits of mutualism should ultimately be measured in terms of a direct fitness measure such as the number of offspring produced (e.g, Cushman and Beattie 1991). For aphids, the present study is the first to follow single individuals throughout their life, both in the presence and the absence of tending ants. In the field, recently founded aphid colonies often consist of one or a few individuals, in particular when the winged foundress has died (W. W. Weisser, personal observation). The main result of our experiment is that ant tending positively affected all measures of aphid fitness. Ant-tended individuals of $M$. fuscoviride lived on average $78 \%$ longer, needed $\sim 10 \%$ less time to mature, gave birth to offspring at a rate that was $88 \%$ higher, and had an expected number of offspring that was more than five times higher than that of individuals not tended by ants. These results are in accordance with previous studies showing that associations with ants can confer fitness benefits to tended aphid colonies (e.g., Herzig 1937, El-Ziady and Kennedy 1956, Banks 1958, El-Ziady 1960, Way 1963, Buckley 1987a, b, Bristow 1991, Dixon 1998, Stadler and Dixon 1999).

Although the benefits of ant tending to aphid colonies are well documented, the selection pressures acting on aphid individuals are poorly understood. Previous studies have found that the main benefit for aphids was protection of aphid colonies from natural enemies (e.g., Banks 1962, Way 1963, Banks and Macaulay 1967, Tilles and Wood 1982, Buckley 1987a, $b$, Dixon 1998). Experiments conducted in the absence of natural enemies often failed to find a positive effect of ant tending on aphid reproduction or fecundity (Banks 1958, Takeda et al. 1982, Bristow 1984, Breton and Addicott 1992b). For the facultatively tended aphid Aphis fabae cirsiiacanthoides, Stadler and Dixon (1998) even reported a detrimental effect of ant tending on fitness-related traits such as developmental time or mean relative growth rate of individuals.

There are several differences between previous studies and our study. First, all previous experiments reared aphids in smaller or larger groups. Because the beneficial effects of ant tending on aphid fitness may depend on the size of the aphid population (e.g., Breton and Addicott 1992a), effects of group size could not be excluded in previous studies. The results of Breton and Addicott (1992a) suggest that ant tending may benefit small aphid populations or individual aphids directly, possibly through a stimulation of their feeding rate, and that the decline of direct effects of ants on aphids is probably due to a decline in the relative number of ants tending aphids at higher aphid densities. Second, different aphid species may respond differently to the 
presence of ants. For instance, successful colonies of A. $f$. cirsiiacanthoides are often found in the absence of ants (Stadler and Dixon 1998), whereas field observations suggest that $M$. fuscoviride depends more on the presence of ants (W. W. Weisser, personal observation). This might be a consequence of speciesspecific differences in investment into securing tending by ants (see discussion below). Third, selection pressures exerted by natural enemies may differ for different aphid species. We can expect selection to favor ant tending only if the costs to tended individuals are smaller than the benefits. If predation pressure is high, the advantages of being protected by ant workers may outweigh any negative effects ants might have on aphid life history in the absence of natural enemies (cf. Stadler and Dixon 1999). In the case of $M$. fuscoviride, aphids benefit from ant tending even in the absence of natural enemies. Thus, to understand aphid-ant mutualism it is necessary to study the effect of ants on aphid fitness both in the presence and absence of natural enemies. Testable predictions concerning the effect of ants on the life history of a particular aphid species will therefore depend on the importance of natural enemies in the life cycle of this species.

Aphid individuals were regularly tended by up to four or five ants at a time in our experiment. There were no significant differences in the mean number of workers tending the aphids at the level of the ant colony. However, one interesting result is the strong positive correlation between the rate of ant tending and aphid survival (Fig. 2). There was also a positive correlation between honeydew production and survival, and between life span and lifetime fecundity for untended aphids. These results are consistent with the hypothesis that individual aphids vary in "quality" in some way such that "high-quality" aphids feed more, produce more honeydew, live longer and have a higher lifetime fecundity than "low-quality" aphids. In the presence of ants, high-quality aphids are tended more intensively by ants, which may further improve their survival for some unknown reason. In our experiment, variation in aphid quality may have been caused by variation in feeding rates, feeding sites on plants, plant quality, or possibly some intrinsic differences among individuals. To identify the underlying causes of the variation in aphid quality, experiments could be performed that assess the quality of the phloem sap and other correlates of host plant quality. Aphid feeding rate and the production, composition, and concentration of the excreted honeydew of individuals could also be measured (e.g., Völkl et al. 1999). However, the proximate causes of improved survival due to the level of ant tending may be more difficult to identify, because quantitative measures of internal physiological parameters may have to be estimated.

Tending may improve aphid survival for several reasons. Removal of honeydew by ants possibly allows individuals of $M$. fuscoviride to increase life span by improving their feeding rate (e.g., Herzig 1937, Banks and Nixon 1958, Mittler 1958, Takeda et al. 1982). Correlational evidence for this hypothesis could be obtained by measuring both feeding rates and life span in an experiment. Aphids may also feed more continuously when tended by ants; the presence of ants may represent a "tranquilizing" cue for aphids (e.g., Way 1963), indicating, for example, that the risk of predation is likely to be low. Finally, ant tending may reduce the risk of fungal attack (Nixon 1951, Buckley 1987a, $b)$. Although three untended aphids were visibly attacked by fungus originating from honeydew droplets prior to their death in the experiment, we were unable to confirm the hypothesis that untended aphids change their feeding sites more often than tended aphids to avoid close contact with excreted honeydew. Thus, it remains unclear whether protection from fungal attack is an important cause for improved survival of aphids in the presence of ants.

The strong effect of $L$. niger on the life history traits of $M$. fuscoviride suggests that the aphids suffer from strong fitness losses if they are not tended by ants. Because homopterans often have to compete for the services of ants (Addicott 1978, 1985, Cushman and Addicott 1989, 1991), M. fuscoviride is expected to invest in securing attendance by ants. A recent study by Völkl et al. (1999) shows that the honeydew of $M$. fuscoviride differs significantly both from the phloem content of T. vulgare and from the honeydew of three other aphid species that also live on tansy. M. fuscoviride produces more honeydew per unit of time, and its honeydew contains a high proportion of trisaccharides that are not found in the phloem sap but are strong attractants for workers of L. niger (Kiss 1981). In choice tests with colonies of several aphid species present, ant workers did preferentially visit plants with colonies of M. fuscoviride (Völkl et al. 1999). Although at present it cannot be excluded that the high rate of honeydew production and the provision of trisaccharides in the honeydew are by-products of physiological processes unrelated to the maintenance of mutualistic relationships, it is possible that they at least partly represent an investment of $M$. fuscoviride into the relationship with attending ants.

Current theory suggests that mutualistic interactions are best viewed as reciprocal exploitations that nevertheless provide net benefits to each partner (Bronstein 1994, Herre et al. 1999). To unravel the conflict of interests in mutualistic systems requires an identification of the costs and benefits at a biologically relevant scale of organisation, which, in most cases, is the level of the individual (Boucher et al. 1982, Boucher 1985, Templeton and Gilbert 1985, Herre et al. 1999). The dependence of aphid fitness on the level of ant tending in addition to the possibility that aphids have to compete for the services of ants by de novo synthesis of ant-attracting substances (cf. Völkl et al. 1999), does, however, also point to a potential conflict of interests 
between the mutualistic partners. Whenever ants stop tending a colony because more profitable sources of carbohydrates are available or the needs of the colony change, the abandoned aphids will suffer high fitness costs. The costs associated with attracting ant workers might be another reason why so few aphids are anttended (Bristow 1991). This hypothesis would be supported if future studies show that both the level of ant tending and the fitness gain to the tended individual is a function of the investment on the part of the aphid.

\section{ACKNOWLEDGMENTS}

We thank Cesare Baroni Urbani and Else-Juliette Fjerdingstad for their advice and help in rearing ants, Marcel Kaiser for providing fruit flies, Christian Braendle for help with the experiment, and Wolfgang Völkl, Bernhard Stadler and Jean-Christophe Simon for stimulating discussions. Comments by Dieter Ebert, Melanie Fischer, Deborah Gordon, Tad Kawecki, Ian Sanders, John Sloggett, Bernhard Stadler, Steve Stearns, Wolfgang Völkl, and two anonymous referees greatly improved the presentation of our results. T. Flatt was supported by the Emilia Guggenheim-Schnurr Foundation and the Swiss Study Foundation, and W. W. Weisser was supported by the Novartis-Stiftung, the Roche Research Foundation, and the Swiss Nationalfonds (grant no. 3100053852.98).

\section{Literature Cited}

Addicott, J. F. 1978. Competition for mutualists: aphids and ants. Canadian Journal of Zoology 56:2093-2096.

Addicott, J. F. 1979. A multispecies aphid-ant association: density dependence and species-specific effects. Canadian Journal of Zoology 57:558-569.

Addicott, J. F. 1985. Competition in mutualistic systems. Pages 217-247 in D. H. Boucher, editor. The biology of mutualism: ecology and evolution. Croom Helm, London, UK.

Banks, C. J. 1958. Effects of the ant, Lasius niger (L.), on the behaviour and reproduction of the black bean aphid, Aphis fabae Scop. Bulletin of Entomological Research 49: 701-714.

Banks, C. J. 1962. Effects of the ant Lasius niger (L.) on insects preying on small populations of Aphis fabae Scop. on bean plants. Annals of Applied Biology 50:669-679.

Banks, C. J., and E. D. M. Macaulay. 1967. Effects of Aphis fabae Scop. and of its attendant ants and insect predators on yields of field beans (Vicia faba L.). Annals of Applied Biology 60:445-453.

Banks, C. J., and H. L. Nixon. 1958. Effects of the ant, Lasius niger L., on the feeding and excretion of the bean aphid, Aphis fabae Scop. Journal of Experimental Biology 35: 703-711.

Börner, C. 1952. Aphidae Europae Centralis. Mitteilungen der Thüringer Botanischen Gesellschaft 4:1-184.

Boucher, D. H. 1985. The idea of mutualism, past and future. Pages 1-28 in D. H. Boucher, editor. The biology of mutualism: ecology and evolution. Croom Helm, London, UK.

Boucher, D. H., S. James, and K. H. Keeler. 1982. The ecology of mutualism. Annual Review of Ecology and Systematics 13:315-347.

Breton, L. M., and J. F. Addicott. 1992a. Density-dependent mutualism in an aphid-ant interaction. Ecology 73:21752180.

Breton, L. M., and J. F. Addicott. 1992b. Does host-plant quality mediate aphid-ant mutualism? Oikos 63:253-259.

Bristow, C. M. 1984. Differental benefits from ant attendance to two species of homoptera on New York ironweed. Journal of Animal Ecology 53:715-726.

Bristow, C. M. 1991. Why are so few aphids ant-tended?
Pages 104-119 in C. R. Huxley and D. F. Cutler, editors. Ant-plant interactions. Oxford University Press, Oxford, UK.

Bronstein, J. L. 1994. Conditional outcomes in mutualistic interactions. Trends in Ecology and Evolution 9:214-217.

Buckley, R. C. 1987a. Interactions involving plants, Homoptera, and ants. Annual Review of Ecology and Systematics 18:111-135.

Buckley, R. C. 1987b. Ant-plant-homopteran interactions. Advances in Ecological Research 16:53-85.

Carrol, C. R., and D. H. Janzen. 1973. Ecology of foraging by ants. Annual Review of Ecology and Systematics 4:231257.

Cushman, J. H., and J. F. Addicott. 1989. Intra- and interspecific competition for mutualists: ants as a limited and limiting resource for aphids. Oecologia 79:315-321.

Cushman, J. H., and J. F. Addicott. 1991. Conditional interactions in ant-plant-herbivore mutualism. Pages 92-103 in C. R. Huxley and D. F. Cutler, editors. Ant-plant interactions. Oxford University Press, Oxford, UK.

Cushman, J. H., and A. J. Beattie. 1991. Mutualisms: assessing the benefits to hosts and visitors. Trends in Ecology and Evolution 6:193-195.

Degen, A. A., M. Gersani, Y. Avivi, and N. Weisbrot. 1986. Honeydew intake of the weaver ant Polyrhachis simplex (Hymenoptera: Formicidae) attending the aphid Chaitophorus populialbae (Homoptera: Aphididae). Insectes Sociaux 33:211-215.

Dixon, A. F. G. 1998. Aphid ecology. Chapman and Hall, London, UK.

El-Ziady, S. 1960. Further effects of Lasius niger L. on Aphis fabae Scopoli. Proceedings of the Royal Entomological Society London (A) 35:30-38.

El-Ziady, S., and J. S. Kennedy. 1956. Beneficial effects of the common garden ant, Lasius niger L., on the black bean aphid, Aphis fabae Scopoli. Proceedings of the Royal Entomological Society London (A) 31:61-65.

Fiedler, K., and U. Maschwitz. 1988. Functional analysis of the myrmecophilous relationships between ants (Hymenoptera: Formicidae) and lycaenids (Lepidoptera: Lycaenidae). II. Lycaenid larvae as trophobiotic partners of ants -a quantitative approach. Oecologia 75:204-206.

Fischer, M. 1997. Hierarchien im Mutualismus zwischen Lasius niger und verschiedenen honigtauproduzierenden Blattlausarten. Diploma thesis. University of Bayreuth, Germany.

Herre, E. A., N. Knowlton, U. G. Mueller, and S. A. Rehner. 1999. The evolution of mutualisms: exploring the paths between conflict and cooperation. Trends in Ecology and Evolution 14:49-53.

Herzig, J. 1937. Ameisen und Blattläuse. Zeitschrift für angewandte Entomologie 24:367-435.

Hölldobler, B., and E. O. Wilson. 1990. The ants. SpringerVerlag, Berlin, Germany.

Keller, L., D. Cherix, and P. Ulloa-Chacon. 1989. Description of a new artificial diet for rearing ant colonies as Iridomyrmex humilis, Monomorium pharaonis and Wasmannia auropunctata (Hymenoptera; Formicidae). Insectes Sociaux 36:348-352.

Kiss, A. 1981. Melizitose, aphids and ants. Oikos 37:382.

Klausnitzer, B. 1968. Zur Kenntnis der Entomofauna von Tanacetum vulgare L. und Artemisia vulgaris L. Wissenschaftliche Zeitschrift der Technischen Universität Dresden 17:19-21.

Mackauer, M., and W. Völkl. 1993. Regulation of aphidiid wasps: Does aphidiid foraging behaviour or hyperparasitism limit impact? Oecologia 94:339-350.

Mitich, L. W. 1992. Intriguing world of weeds-Tansy. Weed Technology 6:242-244.

Mittler, T. E. 1958. The excretion of honeydew by Tubero- 
lachnus salignus (Gmelin). Proceedings of the Royal Entomological Society London (A) 33:49-55.

Nixon, G. E. J. 1951. The association of ants with aphids and coccids. Commonwealth Institute of Entomology, London, UK.

Pierce, N. E., and S. Easteal. 1986. The selective advantage of attendant ants for the larvae of a lycaenid butterfly, Glaucopsyche lygdamus. Journal of Animal Ecology 55:451462.

Pierce, N. E., R. L. Kitching, R. C. Buckley, M. F. J. Taylor, and K. F. Benbow. 1987. The costs and benefits of cooperation between the Australian lycaenid butterfly, Jalmenus evagoras, and its attendant ants. Behavioral Ecology and Sociobiology 21:237-248.

Pierce, N. E., and P. S. Mead. 1981. Parasitoids as selective agents in the symbiosis between lycaenid butterfly larvae and ants. Science 211:1185-1187.

SAS Institute. 1989. SAS/STAT user's guide: basics. Version 6.04. SAS Institute, Cary, North Carolina, USA.

Sokal, R. F., and F. J. Rohlf. 1995. Biometry. W. H. Freeman, New York, New York, USA.

Stadler, B., and A. F. G. Dixon. 1998. Costs of ant attendance for aphids. Journal of Animal Ecology 67:454-459.

Stadler, B., and A. F. G. Dixon. 1999. Ant attendance in aphids: why different degrees of myrmecophily? Ecologica Entomology 24:363-369.
Stearns, S. C. 1992. The evolution of life histories. Oxford University Press, Oxford, UK.

Takeda, S., K. Kinomura, and H. Sakurai. 1982. Effects of ant tending on the honeydew excretion and larviposition of the cowpea aphid, Aphis craccivora Koch. Applied Entomology and Zoology 17:133-135.

Templeton, A. R., and L. E. Gilbert. 1985. Population genetics and the coevolution of mutualism. Pages 128-144 in D. H. Boucher, editor. The biology of mutualism: ecology and evolution. Croom Helm, London, UK.

Tilles, D. A., and D. L. Wood. 1982. The influence of carpenter ant (Camponotus modoc) (Hymenoptera: Formicidae) attendance on the development and survival of aphids (Cinara spp.) (Homoptera: Aphididae) in a giant Sequoia forest. Canadian Entomologist 114:1133-1142.

Völkl, W. 1992. Aphids or their parasitoids: Who actually benefits from ant tending? Journal of Animal Ecology 61: 273-281.

Völkl, W., J. Woodring, M. Fischer, M. W. Lorenz, and K. H. Hoffmann. 1999. Ant-aphid mutualism: the impact of honeydew production and honeydew sugar composition on ant preferences. Oecologia 118:483-491.

Way, M. J. 1963. Mutualism between ants and honeydewproducing Homoptera. Annual Review of Entomology 8: 307-344. 